\title{
Cranial variability of the European Middle Triassic sauropterygian Simosaurus gaillardoti
}

Carlos De Miguel Chaves, Francisco Ortega, and Adán Pérez-García

Acta Palaeontologica Polonica 63 (2), 2018: 315-326 doi:https://doi.org/10.4202/app.00471.2018

Simosaurus is a Triassic eosauropterygian genus known from cranial and postcranial elements, found in the Middle and Upper Triassic strata of Europe and the Middle East. Simosaurus gaillardoti is currently recognised as the only valid species of the genus, identified in Ladinian strata of an area that includes northeastern France (Lorraine) and southwestern Germany (Baden-Württemberg). The remains from this area include more than 20 skulls. Although some of them were described in detail and figured by several authors since the discovery of $S$. gaillardoti, many others remained unpublished. Here we study and figure 25 skulls from this taxon, reviewing the previously known specimens, and presenting and analyzing numerous unpublished skulls. This significant sample of skulls from a single taxon of a European Triassic eosauropterygian allows us to recognise intraspecific variability in characters previously identified as non-variable in this species, including some that are often included in phylogenetic analyses of these reptiles. Therefore, we markedly increase our knowledge of the cranial skeleton in this taxon.

Key words: Sauropterygia, Simosauridae, skulls, Triassic, Ladinian, France, Germany.

Carlos de Miguel Chaves [carlos.miguelchaves@gmail.com], Francisco Ortega [ fortega@ ccia.uned.es ], and Adán Pérez-García [paleontologo@gmail.com], Grupo de Biología Evolutiva, Facultad de Ciencias, UNED, Paseo de la Senda del Rey 9, 28040, Madrid, Spain.

This is an open-access article distributed under the terms of the Creative Commons Attribution License (for details please see creativecommons.org), which permits unrestricted use, distribution, and reproduction in any medium, provided the original author and source are credited. 
FaF Full text $(939.8 \mathrm{kB})$ 